Article

\title{
Formation of a Pd/MgO Structured Catalyst for the Aqueous Oxidation of Silane to Silanol
}

\author{
Jun Zhou ${ }^{1}$, Xiaoqing Cao ${ }^{1}$, Hongna Wang ${ }^{1}$ and Song $\mathrm{Li}^{1,2, * \mathbb{C}}$ \\ 1 Key Lab for Anisotropy and Texture of Materials (MoE), School of Materials Science and Engineering, \\ Northeastern University, Shenyang 110819, China; hafouniu@163.com (J.Z.); caoxiaoqingfly@163.com (X.C.); \\ whnrena@163.com (H.W.) \\ 2 Research Center for Metallic Wires, Northeastern University, Shenyang 110819, China \\ * Correspondence: lis@atm.neu.edu.cn
}

Received: 17 September 2019; Accepted: 30 September 2019; Published: 4 October 2019

\begin{abstract}
The catalytic oxidation of silanes to produce silanols using water as an oxidant at mild temperatures is a major challenge in Si-H activation. Highly efficient and easy-to-recycle catalysts based on Pd nanoparticles are in high demand. In this study, Pd nanoparticles embedded in an $\mathrm{MgO}$ porous overlayer on an $\mathrm{Mg}$ plate as a structured catalyst was prepared by the plasma electrolyte oxidation (PEO) technique. The $\mathrm{Pd} / \mathrm{MgO}$ catalyst is strongly anchored to the $\mathrm{MgO}$ plate, building a structured catalyst. Fabrication parameters such as the temperature of the electrolyte and applied voltage significantly influenced the structure of the obtained $\mathrm{Pd} / \mathrm{MgO}$ catalyst and in turn its catalytic activity. The catalytic activities of $\mathrm{Pd} / \mathrm{MgO}$ were evaluated by activation of a Si-H bond for catalyzing the aqueous oxidation of silanes to silanol at mild temperatures. The catalytic activity of $\mathrm{Pd}$ nanoparticles is favored by their electro-deficient state due to influence from the $\mathrm{MgO}$ substrate. $\mathrm{The} \mathrm{Pd} / \mathrm{MgO}$ catalyst exhibits good performance stability during recycling. This work paves the way for fabricating structured catalysts with long-term stability and enhanced metal-oxide interaction.
\end{abstract}

Keywords: structured catalyst; Pd nanoparticles; metal-oxide interaction; silanol

\section{Introduction}

Noble metal nanoparticles dispersed on porous substrates are the dominate form of catalyst used in both fundamental research and industrial reactions [1]. To reduce the cost of the precious metals and increase the accessible number of reactive sites, metals are downsized into nano or sub-nano scales. Consequently, the metals are thermodynamically unstable due to increased chemical potential [2] and have a strong tendency to grow or sinter [3]. Fabricating nanocatalysts with long-term stability is of importance for practical use. In addition, it has been widely recognized that the support plays more roles than simply providing a surface area. Electronic interactions across the interface have a significant and direct impact on the catalytic activity of the metal nanocatalyst [4,5]. In this scenario, the quality of the metal-support interface is key in order to manipulate their performance even if the metal and the support are the same, as such an interaction can affect only the sites less than $1 \mathrm{~nm}$ away from the interface $[4,6]$. However, metals are simply loaded on the support in most nanocatalysts prepared by conventional solution methods, limiting the metal-support interaction and weakening the metal stability in harsh conditions [7]. To address these problems, we recently developed a plasma electrolytic oxidation (PEO) based method for fabricating metal nanoparticles (NPs) that are strongly adhered to porous oxide [8]. Au NPs obtained by this method are semi-embedded in the oxide and exhibit abnormal thermal stability at relative high temperatures. Such a heterostructure constructed on an $\mathrm{Mg}$ plate forms a structured catalyst that can easily be employed for use. 
Silanols, organic compounds containing Si-OH groups, play a wide and important role in organic synthesis by acting as building blocks for silicon-based polymeric materials, nucleophilic partners in cross-coupling reactions, and directing groups for $\mathrm{C}-\mathrm{H}$ bond activation reactions $[9,10]$. By starting with different precursors, various strategies have been successfully developed for the preparation of silanols. These methods can be categorized into three routes, namely: nucleophilic substitution of siloxanes in the presence of an organic alkali agent, hydrolysis of chlorosilanes, and oxidation of organosilane. Among these three routes, oxidation of silanes attracts the most attention because the precursor is low-cost. Conventionally, strong oxidative agents such as dimethyldioxirane are used to oxidize silanes, but they also produce toxic byproducts [11]. Currently, the attention has been shifted to catalytic oxidation using water or dioxygen as the green oxidants under mild conditions, which is environmentally benign because the only byproduct is $\mathrm{H}_{2}$ or $\mathrm{H}_{2} \mathrm{O}$ [12]. Finding efficient and highly active catalysts for activating $\mathrm{Si}-\mathrm{H}$ under mild conditions is of the utmost importance, and corresponding progress has been made. For example, ultra-small Au NPs dispersed on $\mathrm{MnO}_{2}$ nanowires exhibit high activity for the oxidation of hydrosilanes and $\mathrm{H}_{2}$ production [13]. It was found that positively charged Au species and oxygen vacancies in the oxide support favors the oxidation of silane. To improve the atomic efficiency of the precious metals, the active phases are downsized to sub-nano scale, even to the limit of a single atom. It has been shown that a single Au atom anchored on $\mathrm{C}_{3} \mathrm{~N}_{4}$ can activate the Si-H bond [13]. By comparing several metals, Park and coworkers identified that $\mathrm{Pd}$ NPs supported on aluminum oxyhydroxide outperform others such as $\mathrm{Au}, \mathrm{Rh}, \mathrm{Ru}$, and $\mathrm{Cu}$ [12], and these catalysts can be reused if properly recycled. However, a further separation process is required because these catalysts are in the form of particles, though activities are reasonably good.

In this work, we extend our PEO technique to the fabrication of $\mathrm{Pd} / \mathrm{MgO}$ nanocatalysts and investigate their catalytic performance for the oxidation reaction of silane to produce silanol. Synchronously formed Pd NPs between $2.0-4.4 \mathrm{~nm}$ from precursor decomposition are embedded in the $\mathrm{MgO}$ substrate. The preparation parameters, including the temperature of the electrolyte and applied bias, are investigated to optimize the catalytic activity of the final products. A high catalytic activity of $\mathrm{Pd} / \mathrm{MgO}$ is therefore optimized for converting silane into silanol. Importantly, the operation of the $\mathrm{Pd} / \mathrm{MgO}$ nanocatalyst is simple since it is essentially a structured catalyst [14] on a bulk metallic plate. The catalytic reaction can be quickly switched between on-and-off states by immersing in or taking out the catalyst.

\section{Results and Discussion}

The preparation of the $\mathrm{Pd} / \mathrm{MgO}$ nanocatalyst goes through a one-step interfacial plasma electrolytic oxidation (PEO), which involves two separate but synchronous steps, namely: forming the porous oxide layer on the Mg substrate under high voltage bias and the growth of Pd NPs due to precursor decomposition in the presence of a micro-arc [8]. In the following sections, we investigate the influence of electrolyte temperature and applied bias on the structural characteristics and catalytic activity of the nanocatalyst.

\subsection{Effects of Electrolyte Temperature on Reactivity of Pd Nanocatalysts}

The PEO process has a high-temperature plasma effect that usually generates a lot of heat due to the arc discharge, and would cause severe destruction of the catalyst including both the support and the active phase [15]. To obtain a high-quality catalyst, the heat must be removed promptly during the PEO process from the solid-electrolyte interface region. In fact, the electrolyte plays more roles than serving as an arcing mediator. The temperature of the electrolyte as well as its flow feature affect the cooling rate in the arcing region and consequently the morphology of the oxide layer [8]. In this section, we systematically study the effect of electrolyte temperature on the catalytic performance of the obtained $\mathrm{Pd} / \mathrm{MgO}$ catalyst. Three electrolyte temperatures $\left(3{ }^{\circ} \mathrm{C}, 10^{\circ} \mathrm{C}\right.$, and $\left.23^{\circ} \mathrm{C}\right)$ are selected to perform the PEO process. As shown in Figure 1, the acquired $\mathrm{Pd} / \mathrm{MgO}$ catalyst has an excellent 
catalytic performance including the highest silanol yield (85\%, $120 \mathrm{~min})$ and turnover frequency (TOF) for samples prepared in $10^{\circ} \mathrm{C}$ electrolyte.
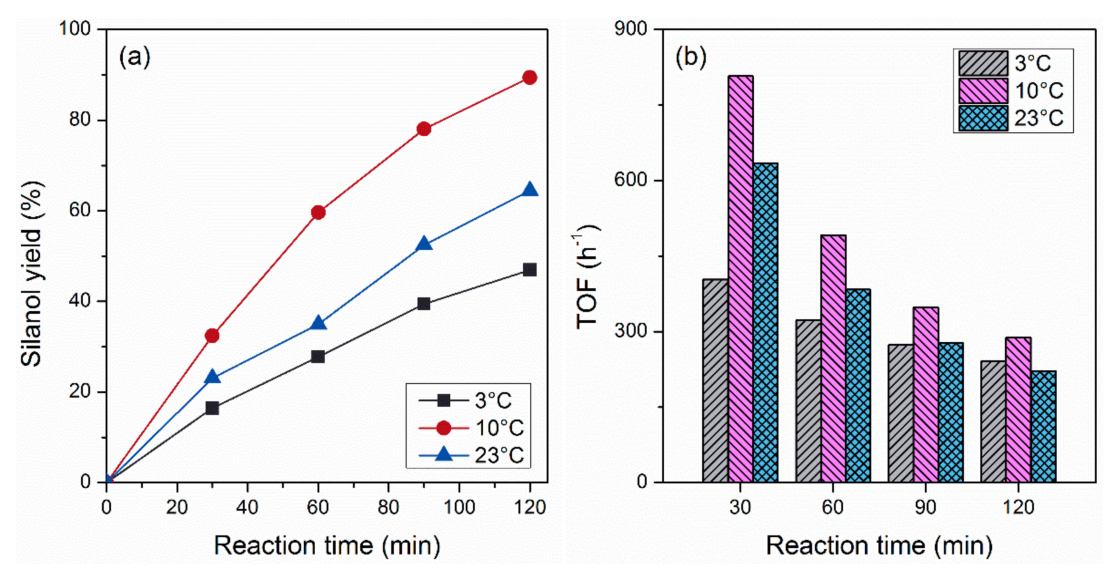

Figure 1. Yield of silanol (a) and corresponding turnover frequency (TOF) (b) during the reaction process catalyzed by $\mathrm{Pt}$ nanocatalysts fabricated in electrolytes of different temperatures.

To further explore the reason for their different catalytic activities, scanning electron microscopy (SEM) characterization was performed to observe their morphology and structure, as shown in Figure 2. The surface of the $\mathrm{Pd} / \mathrm{MgO}$ catalyst prepared in $10{ }^{\circ} \mathrm{C}$ electrolyte has a large uniformly distributed pore, which favors the diffusion of the reactant into holes to contact the Pd nanoparticles. For the other two catalysts prepared in $3{ }^{\circ} \mathrm{C}$ and $23^{\circ} \mathrm{C}$ electrolyte, they show an obvious difference in surface structure compared to the sample prepared in $10^{\circ} \mathrm{C}$ electrolyte. The former has a smaller pore size and non-uniform pore distribution due to low electrolyte temperature (weak arcing discharge). The surface structure of the latter sample is partially destroyed, leading to a multilayered structure deriving from the drastic arcing discharge effect (the high electrolyte temperature that weakens the heat transfer effect between the electrolyte and the arcing region). These structural features are not favorable for catalytic reactions and therefore the final products exhibit relatively lower catalytic activity. Therefore, appropriate electrolyte temperature is crucial for fabricating high activity $\mathrm{Pd} / \mathrm{MgO}$ catalysts by the PEO process.
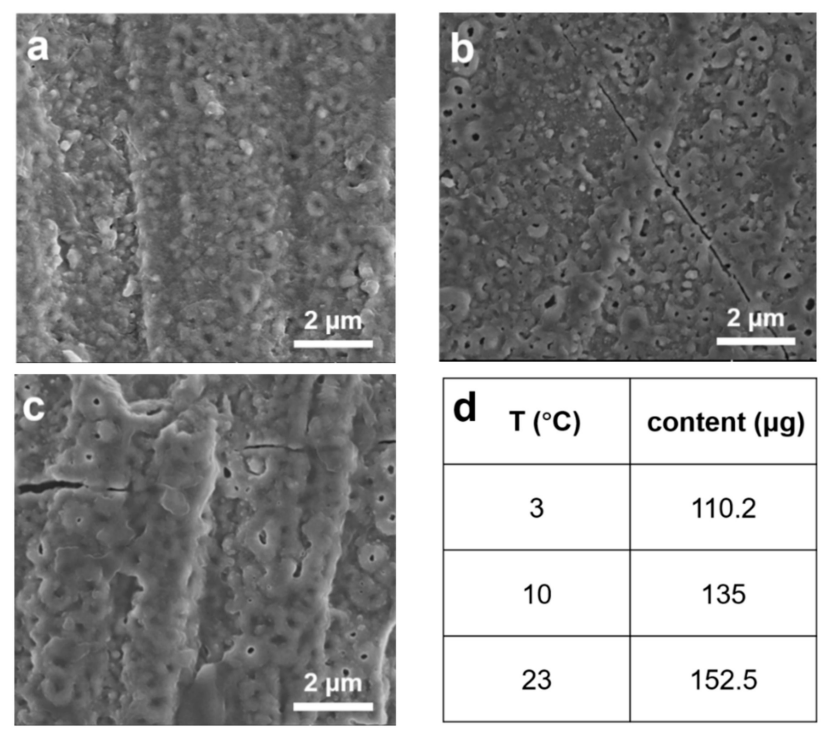

\begin{tabular}{|c|c|}
\hline d $\mathrm{T}\left({ }^{\circ} \mathrm{C}\right)$ & content $(\mu \mathrm{g})$ \\
\hline 3 & 110.2 \\
\hline 10 & 135 \\
\hline 23 & 152.5 \\
\hline
\end{tabular}

Figure 2. (a-c) Top view morphology of the MgO supported nanocatalysts prepared by plasma electrolyte oxidation (PEO) at different electrolyte temperatures. (d) Loading content of Pd in the sample. 


\subsection{Influence of Applied Voltage on the Performance of PEO Prepared Nanocatalysts}

In the PEO process, the applied voltage is important as it regulates the arcing discharge, which determines the catalyst size and structure. In this section, three different voltages $(300 \mathrm{~V}, 400 \mathrm{~V}, 500 \mathrm{~V})$ were applied to the PEO process and the acquired $\mathrm{Pd} / \mathrm{MgO}$ catalyst exhibited different particle size and catalytic activity. Figure 3 shows the plot of silanol yield vs. reaction using three catalysts. It is found that the sample prepared in $300 \mathrm{~V}$ applied voltage exhibits the highest silanol yield and reaction rate compared to the other two catalysts prepared in $400 \mathrm{~V}$ and $500 \mathrm{~V}$, respectively. This obvious advantage is mainly ascribed to the low relative applied voltage that is closely related to the arcing discharge during the PEO process $[16,17]$. SEM characterization results show that the pore size of the catalyst surface gradually increased accompanied with a reduction in pore number when the applied voltage is increased from $300 \mathrm{~V}$ to $500 \mathrm{~V}$. Detailed information is illustrated in Supplementary Materials Figure S1. In fact, the catalyst precursor $\mathrm{PdCl}_{2}$ in the electrolyte was decomposed into corresponding metallic $\mathrm{Pd}$ due to the high-temperature arcing discharge [18]. Therefore, the intensity of arcing is crucial for determining particle size and their catalytic performance. The excessive high applied voltage generates the drastic arcing discharge that causes the Pd nanoparticle to coalesce and grow [15], which is unfavorable for the catalytic reaction due to the reduced number of active atoms in Pd nanoparticles [19]. Also, high-angle annular dark-field scanning transmission electron microscopy (HAADF-STEM ) observation shows that the acquired Pd nanoparticles have different sizes and monodispersity when different voltages are applied. As shown in Figure 4, the particle size gradually increases from $2.0 \mathrm{~nm}$ to $4.4 \mathrm{~nm}$ with increased applied voltage while accompanied by reduced monodisperity. $\mathrm{Pd} / \mathrm{MgO}$ prepared with $300 \mathrm{~V}$ applied voltage has a small particle size $(2.0 \mathrm{~nm})$ and high monodispersity. Moreover, the obtained $\mathrm{Pd}$ nanoparticles have a homogeneous distribution on the $\mathrm{MgO}$, as shown in Figure 4a. According to the literature, the particle size, monodisperity and distribution are also important factors for catalytic activity [20-22]. Therefore, a relatively low applied voltage is required to generate the weak micro-arc discharge that facilitates achieving a gentle precursor decomposition process, which would moderate particle aggregation and finally realize the control of NP nucleation and growth. Notably, the samples characterized by XRD indicate only substrate $\mathrm{Mg}$ and support $\mathrm{MgO}$ without $\mathrm{Pd}$, as shown in Figure $4 \mathrm{~d}$. We conclude that the main reason for this is that the Pd content in the sample is too low to detect.
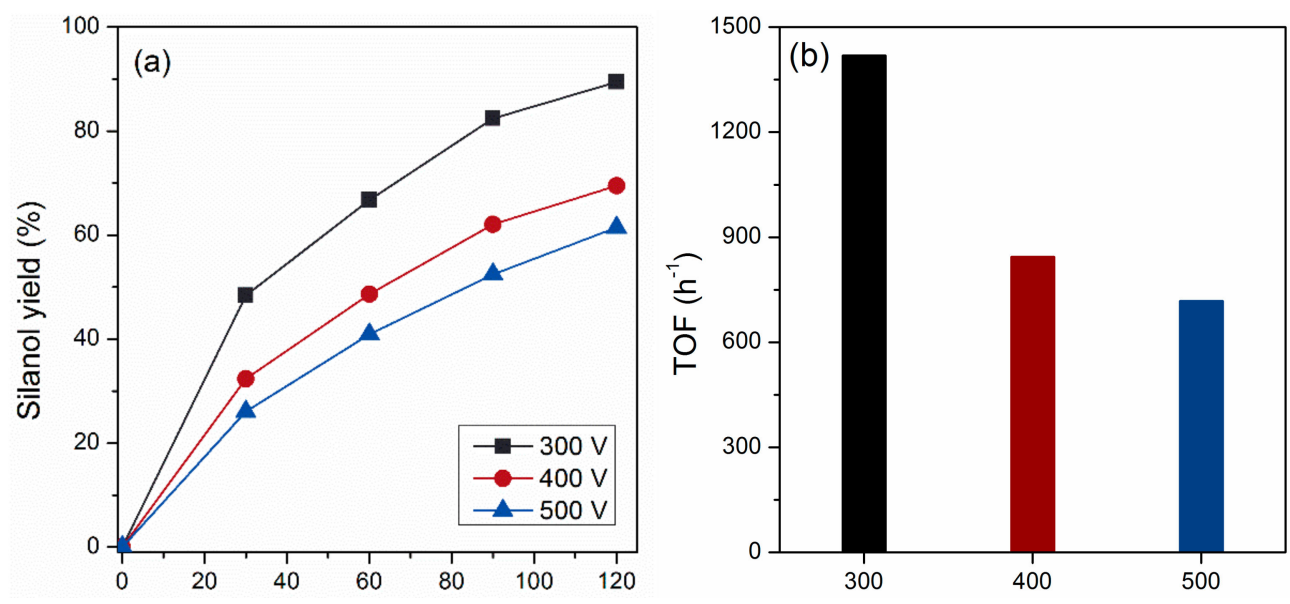

Figure 3. (a) The plot of silanol yield vs. reaction time for the $\mathrm{Pd} / \mathrm{MgO}$ catalysts prepared by different applied voltages. (b) TOF of the reaction catalyzed by the $\mathrm{Pd} / \mathrm{MgO}$ catalyst prepared by different applied voltages. 



Figure 4. Transmission electron microscopy (TEM) images of $\mathrm{Pd} / \mathrm{MgO}$ catalysts prepared by different applied voltages (a) $300 \mathrm{~V}$, (b) $400 \mathrm{~V}$, (c) $500 \mathrm{~V}$; (d) XRD spectra of Pd/MgO catalysts prepared by different voltages.

\subsection{Influence of the Chemical States of Pd}

For catalytic reaction, the chemical state of the catalytic active species is very important, deriving from their electron effect [23,24]. In our experiment, the sample prepared by the PEO process is treated with $\mathrm{H}_{2}$ reduction at $400{ }^{\circ} \mathrm{C}$ for $2 \mathrm{~h}$. Catalytic reaction results show that the sample treated with thermal reduction possesses a better silanol yield and reaction rate, as shown in Figure 5 . In the PEO process, the surface temperature of the metal Mg plate usually reaches $2000 \mathrm{~K}$, which causes the acquired Pd nanoparticles to become easily oxidized and leads to a reduced catalytic activity. Hence, thermal reduction is required for the prepared $\mathrm{Pd} / \mathrm{MgO}$ catalyst in order to acquire a high catalytic performance. According to the literature, the $\mathrm{Pd}$ species with zero valent state is the primary active phase [25]. In order to investigate the chemical state of the catalyst, $X$-ray photoelectron spectroscopy (XPS) measurement was performed to characterize the catalyst. As shown in Figure 6, the catalyst mainly includes $\mathrm{Mg}, \mathrm{O}, \mathrm{Si}, \mathrm{F}$ and $\mathrm{Pd}$ elements, which are derived from the $\mathrm{MgO}$ support, electrolyte and Pd nanoparticles, respectively. The XPS fine spectrum of the Pd element shows the binding energy of $\mathrm{Pd} 3 \mathrm{~d}_{5 / 2}(335.4 \mathrm{eV})$. After thermal reduction treatment, this shifts to a lower value compared with the corresponding peak position $(336.3 \mathrm{eV})$ in the original sample. Thus, it is clear that the Pd species in the original sample changes from an oxidation state while recovering to the metallic state after treatment with thermal reduction [25], which will largely improve the catalytic activity.

\subsection{Cycling Stability and Convenience}

Recyclability plays an important role in the catalyst field, especially for industrial applications. Here, 12 cycles of the reaction are performed and the results show that the silanol yield remains at $95 \%$ even through 12 cycles of the reaction, which indicates the prepared $\mathrm{Pd} / \mathrm{MgO}$ has excellent recyclability 
and catalytic stability, as shown in Figure 7. The possible reason for this is ascribed to the strong interaction between $\mathrm{Pd}$ and $\mathrm{MgO}$ which has been reported in our previous work [8]. Also, the $\mathrm{Pd} / \mathrm{MgO}$ catalyst prepared by this $\mathrm{PEO}$ approach has a unique advantage compared to other powder catalysts. It is very easy to separate the catalyst from the reaction solution due to the structure of the catalyst: $\mathrm{Pd} / \mathrm{MgO}$ on a bulk metallic Mg plate. Therefore, we could switch on or switch off functionality at any time by taking out or immersing the plate into the reaction solution.

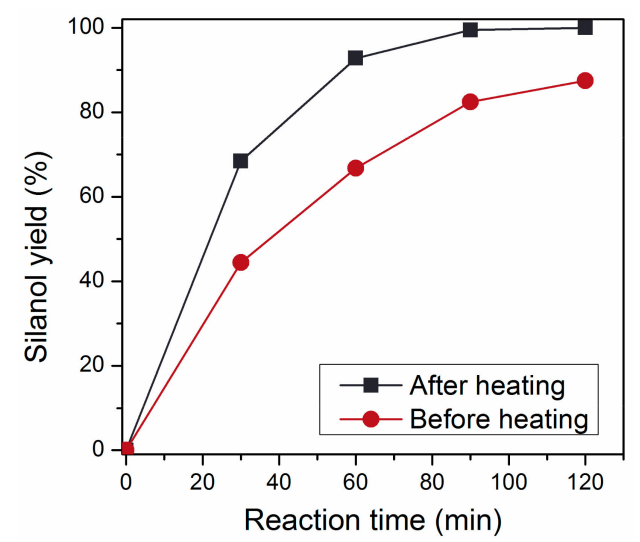

Figure 5. Yield curve of Pd nanocatalysts before and after thermal reduction.
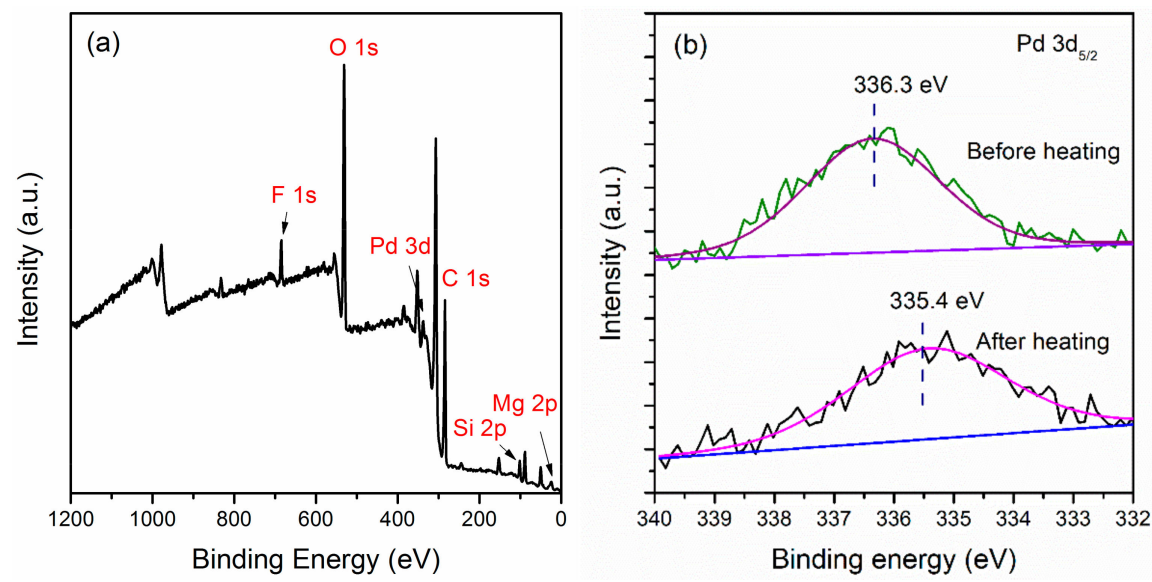

Figure 6. (a) X-ray photoelectron spectroscopy (XPS) spectra of the prepared Pd/MgO catalyst. (b) XPS fine spectrum of the Pd element before and after thermal reduction.

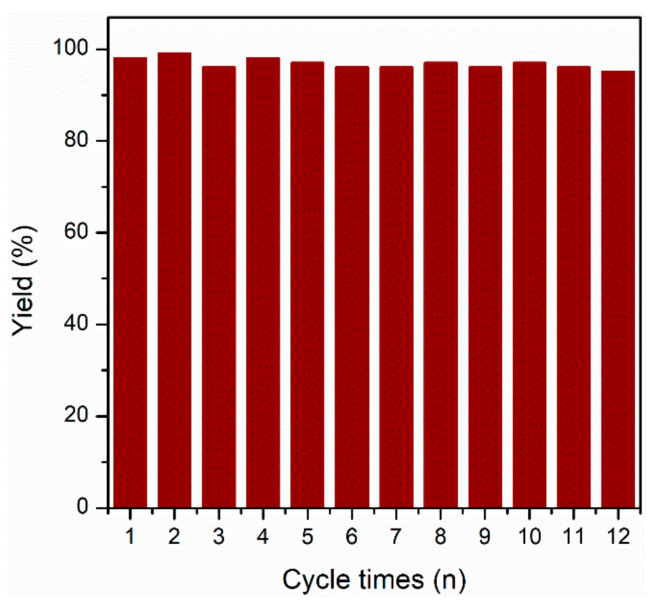

Figure 7. The plot of silanol yield vs. the number of cycles for the prepared $\mathrm{Pd} / \mathrm{MgO}$ catalyst by the PEO process. 


\section{Experimental Methods}

\subsection{Materials}

Sodium metasilicate $\left(\mathrm{Na}_{2} \mathrm{SiO}_{3} 9 \mathrm{H}_{2} \mathrm{O}\right)$, potassium fluoride $(\mathrm{KF})$, potassium hydroxide $(\mathrm{KOH})$ and acetone $\left(\mathrm{CH}_{3} \mathrm{COCH}_{3}\right)$ were purchased from Aladdin and were used as received. Palladium chloride $\left(\mathrm{PdCl}_{2}\right)$, dimethylphenylsilane $\left(\mathrm{C}_{8} \mathrm{H}_{12} \mathrm{Si}\right)$, dimethylphenylsilanol $\left(\mathrm{C}_{8} \mathrm{H}_{12} \mathrm{OSi}\right)$ and ethylbenzene $\left(\mathrm{C}_{6} \mathrm{H}_{5} \mathrm{C}_{2} \mathrm{H}_{5}\right)$ were obtain from Sigma-Aldrich Co., Ltd. (St. Louis, MO, USA) and were used without any purification. The bulk metal $\mathrm{Mg}$ was cut into a plate $(40 \mathrm{~mm} \times 20 \mathrm{~mm} \times 2 \mathrm{~mm})$ by wire-electrode cutting technology. Prior to use, the Mg plate was polished and rinsed with ethanol.

\subsection{Methods}

The $\mathrm{Pd} / \mathrm{MgO}$ heterogeneous catalyst was prepared by the PEO method, which has been reported in our previous work. The clean metal $\mathrm{Mg}$ plate and a stainless-steel plate were used as the anode and cathode, respectively. Firstly, two metal plates were immersed into the electrolyte $\left(4 \mathrm{~g} \mathrm{~L}^{-1} \mathrm{Na}_{2} \mathrm{SiO}_{3}\right.$, $3.5 \mathrm{~g} \mathrm{~L}^{-1} \mathrm{KOH}, 2.5 \mathrm{~g} \mathrm{~L}^{-1} \mathrm{KF}$ and $0.08 \mathrm{~g} \mathrm{~L}^{-1} \mathrm{PdCl}_{2}$ in $500 \mathrm{~mL}$ water; $1 \mathrm{~g} \mathrm{PdCl}_{2}$ has been dissolved in $\mathrm{HCl}$ solution previously) and subjected to the $\mathrm{PEO}$ procedure. After that, the obtained catalyst $(\mathrm{Pd} / \mathrm{MgO}$ loaded on the $\mathrm{Mg}$ plate) was rinsed with water and dried in a vacuum at $30^{\circ} \mathrm{C}$ for $2 \mathrm{~h}$.

\subsubsection{Preparation of the $\mathrm{Pd} / \mathrm{MgO}$ Catalyst Using Different Electrolyte Temperatures}

Three temperatures for the PEO electrolyte were prepared at $23^{\circ} \mathrm{C}, 10^{\circ} \mathrm{C}$ and $3{ }^{\circ} \mathrm{C}$, respectively. The PEO process was set to paragraph boosting voltage mode: frequency $\mathrm{f}=500 \mathrm{~Hz}$, pulse length $=60$; the initial applied voltage was $200 \mathrm{~V}$, which will last $10 \mathrm{~s}$, followed by an increase to $380 \mathrm{~V}$ for the last 15 s. Finally, we obtained three $\mathrm{Pd} / \mathrm{MgO}$ catalysts according to the different temperatures of electrolyte.

\subsubsection{Preparation of the $\mathrm{Pd} / \mathrm{MgO}$ Catalyst Using Different Applied Voltages}

In this section, the PEO working mode was similar to that described above for paragraph boosting voltage mode (frequency $\mathrm{f}=500 \mathrm{~Hz}$, pulse length $=60$, initial voltage $=200 \mathrm{~V}$ for $10 \mathrm{~s}$ ). The only difference is for the increased voltage, which was set to $300 \mathrm{~V}, 400 \mathrm{~V}$, or $500 \mathrm{~V}$, respectively, for $5 \mathrm{~s}$. The electrolyte temperature was controlled at $10{ }^{\circ} \mathrm{C}$, and three $\mathrm{Pd} / \mathrm{MgO}$ catalysts were obtained by different applied voltages.

\subsubsection{Sample Characterization}

The obtained catalyst was characterized by SEM, HAADF-STEM, XRD and XPS, respectively. The surface morphology and structure of the samples were measured by SEM (XL-30 ESEM FEG, FEI). XRD (SmartLab, Rigaku) was used to measure the main chemical component of the catalyst sample prepared in different voltages and temperatures. The size, dispersion and distribution of the Pd nanoparticles on the support were characterized by a HAADF-scanning transmission electron microscope (STEM; JEOL ARM200F). The sample was firstly polished to $80 \mu \mathrm{m}$ and cut into wafers $(\mathrm{d}=3 \mathrm{~mm})$; after rubbing to $15 \mu \mathrm{m}$, the sample was treated with an ion thinning system $(4.5 \mathrm{~V}$ for $1.5 \mathrm{~h}$; $3.5 \mathrm{~V}$ for $1 \mathrm{~h}$ ). X-ray photoelectron spectroscopy (XPS; ESCALAB 250Xi, Thermo Fisher Scientific) was performed to characterize the chemical state of the $\mathrm{Pd} / \mathrm{MgO}$ catalyst before and after thermal reduction treatment.

\subsubsection{Catalytic Reaction}

The catalytic performance of the prepared $\mathrm{Pd} / \mathrm{MgO}$ catalyst was evaluated for the conversion of silane to silanol. Dimethylphenylsilane $(100 \mu \mathrm{L})$ was mixed with $10 \mathrm{~mL}$ acetone, $48 \mu \mathrm{L}$ ethylbenzene and $500 \mu \mathrm{L}$ water in a flask. Once the $\mathrm{Pd} / \mathrm{MgO}$ plate was immersed in the mixed solution, the reaction was triggered under oxygen atmosphere and magnetic stirring. During the catalytic reaction, $500 \mu \mathrm{L}$ of the reaction liquid was pulled out at intervals of $30 \mathrm{~min}$ and used for gas chromatography detection. 
The detection conditions were as follows: HP-5 chromatographic column, temperature $=40^{\circ} \mathrm{C}$ retained for $0.5 \mathrm{~min}$, then increased to $220^{\circ} \mathrm{C}$ by $20^{\circ} \mathrm{C} \mathrm{min}^{-1}$.

\section{Conclusions}

In summary, $\mathrm{Pd} / \mathrm{MgO}$ catalysts were prepared by micro-arc oxidation of an $\mathrm{Mg}$ plate in the electrolyte-containing $\mathrm{Pd}$ precursor. Pd nanoparticles resulting from the decomposition of the corresponding salt were embedded in the $\mathrm{MgO}$ oxide substrate, and the microstructure of the catalyst could be tuned by varying the temperature of the electrolyte and applied bias. The $\mathrm{Pd} / \mathrm{MgO}$ catalyst prepared in electrolyte at $10{ }^{\circ} \mathrm{C}$ with a bias potential of $300 \mathrm{~V}$ exhibited the highest activity for the catalytic oxidation of silane to silanol. After thermal reduction, the full conversion of silane was realized in $120 \mathrm{~min}$, demonstrating that $\mathrm{Pd} / \mathrm{MgO}$ catalysts were $\mathrm{Pd}^{0}$ based nanocatalysts that were influenced by the Pd-MgO interaction. This work proposes a new direction to develop structured catalysts that can easily be recycled.

Supplementary Materials: The following are available online at http://www.mdpi.com/2073-4344/9/10/834/s1, Figure S1: SEM images of $\mathrm{Pd} / \mathrm{MgO}$ catalysts prepared by different applied voltages.

Author Contributions: J.Z. and X.C. performed the catalyst preparation; H.W. is concentrated on the materials characterization. J.Z. and S.L. wrote the manuscript and revised.

Funding: This research was funded by the National Natural Science Foundation of China (grant number 51601032, 51771047), Provincial science and technology project/doctor start fund (20170520385). S Li and J Zhou thanks the Fundamental Research Funds for the Central Universities (N180204014, N170204015).

Conflicts of Interest: The authors declare no conflict of interest.

\section{References}

1. Zhang, J.; Wang, L.; Zhang, B.; Zhao, H.; Kolb, U.; Zhu, Y.; Liu, L.; Han, Y.; Wang, G.; Wang, C.; et al. Sinter-resistant metal nanoparticle catalysts achieved by immobilization within zeolite crystals via seed-directed growth. Nat. Catal. 2018, 1, 540-546. [CrossRef]

2. Campbell, C.T.; Mao, Z. Chemical Potential of Metal Atoms in Supported Nanoparticles: Dependence upon Particle Size and Support. ACS Catal. 2017, 7, 8460-8466. [CrossRef]

3. Grillo, F.; Moulijn, J.A.; Kreutzer, M.T.; van Ommen, J.R. Nanoparticle sintering in atomic layer deposition of supported catalysts: Kinetic modeling of the size distribution. Catal. Today 2018, 316, 51-61. [CrossRef]

4. Liu, Y.; Chen, H.; Xu, C.; Sun, Y.; Li, S.; Jiang, M.; Qin, G. Control of Catalytic Activity of Nano-Au through Tailoring the Fermi Level of Support. Small 2019, 15, 1901789. [CrossRef] [PubMed]

5. Wang, Y.; Cao, F.; Lin, W.; Zhao, F.; Zhou, J.; Li, S.; Qin, G. In situ synthesis of Ni/NiO composites with defect-rich ultrathin nanosheets for highly efficient biomass-derivative selective hydrogenation. J. Mater. Chem. A 2019, 7, 17834-17841. [CrossRef]

6. Suchorski, Y.; Kozlov, S.M.; Bespalov, I.; Datler, M.; Vogel, D.; Budinska, Z.; Neyman, K.M.; Rupprechter, G. The role of metal/oxide interfaces for long-range metal particle activation during $\mathrm{CO}$ oxidation. Nat. Mater. 2018, 17, 519-522. [CrossRef]

7. Li, J.; Song, S.; Long, Y.; Wu, L.; Wang, X.; Xing, Y.; Jin, R.; Liu, X.; Zhang, H. Investigating the hybrid-structure-effect of $\mathrm{CeO}_{2}$-encapsulated $\mathrm{Au}$ nanostructures on the transfer coupling of nitrobenzene. Adv. Mater. 2018, 30, 1704416. [CrossRef]

8. Cao, X.; Zhou, J.; Wang, H.; Li, S.; Wang, W.; Qin, G. Abnormal thermal stability of sub-10 nm Au nanoparticles and their high catalytic activity. J. Mater. Chem. A 2019, 7, 10980-10987. [CrossRef]

9. Murugavel, R.; Walawalkar, M.G.; Dan, M.; Roesky, H.W.; Rao, C.N.R. Transformations of Molecules and Secondary Building Units to Materials: A Bottom-Up Approach. Acc. Chem. Res. 2004, 37, 763-774. [CrossRef]

10. Denmark, S.E.; Werner, N.S. Cross-Coupling of Aromatic Bromides with Allylic Silanolate Salts. J. Am. Chem. Soc. 2008, 130, 16382-16393. [CrossRef]

11. Ishimoto, R.; Kamata, K.; Mizuno, N. Highly Selective Oxidation of Organosilanes to Silanols with Hydrogen Peroxide Catalyzed by a Lacunary Polyoxotungstate. Angew. Chem. Int. Ed. 2009, 48, 8900-8904. [CrossRef] [PubMed] 
12. Jeon, M.; Han, J.; Park, J. Transformation of Silanes into Silanols using Water and Recyclable Metal Nanoparticle Catalysts. Chem CatChem 2012, 4, 521-524. [CrossRef]

13. Da Silva, A.G.M.; Kisukuri, C.M.; Rodrigues, T.S.; Candido, E.G.; de Freitas, I.C.; da Silva, A.H.M.; Assaf, J.M.; Oliveira, D.C.; Andrade, L.H.; Camargo, P.H.C. $\mathrm{MnO}_{2}$ nanowires decorated with Au ultrasmall nanoparticles for the green oxidation of silanes and hydrogen production under ultralow loadings. Appl. Catal. B Environ. 2016, 184, 35-43. [CrossRef]

14. Porsin, A.V.; Kulikov, A.V.; Rogozhnikov, V.N.; Serkova, A.N.; Salanov, A.N.; Shefer, K.I. Structured reactors on a metal mesh catalyst for various applications. Catal. Today 2016, 273, 213-220. [CrossRef]

15. Sankara Narayanan, T.S.N.; Park, I.S.; Lee, M.H. Strategies to improve the corrosion resistance of microarc oxidation (MAO) coated magnesium alloys for degradable implants: Prospects and challenges. Prog. Mater. Sci. 2014, 60, 1-71. [CrossRef]

16. Cheng, Y.; Qin, T.; Li, L.; Wang, H.; Zhang, Z. Comparison of corrosion resistance of microarc oxidation coatings prepared with different electrolyte concentrations on AM60 magnesium alloy. Corros. Eng. Sci. Technol. 2011, 46, 17-23. [CrossRef]

17. Shi, L.; Xu, Y.; Li, K.; Yao, Z.; Wu, S. Effect of additives on structure and corrosion resistance of ceramic coatings on Mg-Li alloy by micro-arc oxidation. Curr. Appl. Phys. 2010, 10, 719-723. [CrossRef]

18. Khaselev, O.; Weiss, D.; Yahalom, J. Structure and composition of anodic films formed on binary Mg-Al alloys in $\mathrm{KOH}$-aluminate solutions under continuous sparking. Corros. Sci. 2001, 43, 1295-1307. [CrossRef]

19. Haruta, M. Chance and necessity: My encounter with gold catalysts. Angew. Chem. Int. Ed. 2014, 53, 52-56. [CrossRef]

20. Ishida, T.; Kinoshita, N.; Okatsu, H.; Akita, T.; Takei, T.; Haruta, M. Influence of the Support and the Size of Gold Clusters on Catalytic Activity for Glucose Oxidation. Angew. Chem. Int. Ed. 2008, 47, 9265-9268. [CrossRef]

21. Lopez, N. On the origin of the catalytic activity of gold nanoparticles for low-temperature CO oxidation. J. Catal. 2004, 223, 232-235. [CrossRef]

22. Taketoshi, A.; Haruta, M. Size- and Structure-specificity in Catalysis by Gold Clusters. Chem. Lett. 2014, 43, 380-387. [CrossRef]

23. Ling, T.; Yan, D.-Y.; Wang, H.; Jiao, Y.; Hu, Z.; Zheng, Y.; Zheng, L.; Mao, J.; Liu, H.; Du, X.-W.; et al. Activating cobalt(II) oxide nanorods for efficient electrocatalysis by strain engineering. Nat. Commun. 2017, 8, 1509. [CrossRef] [PubMed]

24. Strasser, P.; Koh, S.; Anniyev, T.; Greeley, J.; More, K.; Yu, C.; Liu, Z.; Kaya, S.; Nordlund, D.; Ogasawara, H.; et al. Lattice-strain control of the activity in dealloyed core-shell fuel cell catalysts. Nat. Chem. 2010, 2, 454-460. [CrossRef]

25. Shimizu, K.; Kubo, T.; Satsuma, A. Surface Oxygen-Assisted Pd Nanoparticle Catalysis for Selective Oxidation of Silanes to Silanols. Chem. A Eur. J. 2012, 18, 2226-2229. [CrossRef] [PubMed]

(C) 2019 by the authors. Licensee MDPI, Basel, Switzerland. This article is an open access article distributed under the terms and conditions of the Creative Commons Attribution (CC BY) license (http://creativecommons.org/licenses/by/4.0/). 